\title{
Influence of Service Levels and COVID-19 on Water Supply Inequalities of Community-Managed Service Providers in Nepal
}

\author{
Arati Shrestha (D), Shinobu Kazama (D) and Satoshi Takizawa *(D) \\ Department of Urban Engineering, Graduate School of Engineering, The University of Tokyo, Bunkyo-Ku, \\ Tokyo 113-8654, Japan; aratishrestha2012@gmail.com (A.S.); kazama@env.t.u-tokyo.ac.jp (S.K.) \\ * Correspondence: takizawa@env.t.u-tokyo.ac.jp
}

Citation: Shrestha, A.; Kazama, S.; Takizawa, S. Influence of Service Levels and COVID-19 on Water Supply Inequalities of Community-Managed Service Providers in Nepal. Water 2021, 13, 1349. https://doi.org/10.3390/ w13101349

Academic Editor: Julio Berbel

Received: 28 March 2021

Accepted: 10 May 2021

Published: 13 May 2021

Publisher's Note: MDPI stays neutral with regard to jurisdictional claims in published maps and institutional affiliations.

Copyright: (c) 2021 by the authors. Licensee MDPI, Basel, Switzerland. This article is an open access article distributed under the terms and conditions of the Creative Commons Attribution (CC BY) license (https:// creativecommons.org/licenses/by/ $4.0 /)$.

\begin{abstract}
In Nepal, there are three types of water service providers; two types of governmentmanaged service providers covering urban and municipal areas, and community-managed service providers called Water Users and Sanitation Associations (WUSAs). This study aims to assess the current water supply service levels and water supply inequalities of WUSAs in terms of water consumption, supply hours, and customer satisfaction. Among the three types of water service providers, WUSAs offered the best performance in terms of their low non-revenue water (NRW) rates and production costs, high bill collection rates, and long supply hours. During the COVID19 lockdown, water consumption increased, but bill payment notably decreased, possibly due to restricted movement and hesitation by customers to make payments. The multiple-year water consumption variations illustrated the uneven water consumption behavior of customers. Despite the variation in water supply hours, Lorenz curves, Gini coefficients $(G)$, and water consumption analysis depicted low inequalities $(\mathrm{G} \approx 0.20-0.28)$ and adequate water consumption among WUSAs even in 2019-2020. In the three WUSAs, more than $90 \%, 74 \%$, and 38\% of customers consumed water above the basic, medium, and high levels, respectively. Thus, maintaining high service levels of WUSAs is instrumental in achieving Goal 6 of the Sustainable Development Goals (SDGs) in Nepal.
\end{abstract}

Keywords: community-managed systems; COVID-19; online payment; water consumption; inequality

\section{Introduction}

Goal 6 of the Sustainable Development Goals (SDGs) aims to ensure equitable access to safe drinking water for all, thus indicating the importance of sustainable water service management [1,2]. In 2017, 2.2 billion people, i.e., one-third of the global population, were estimated to be living without safely managed drinking water services [3]. Piped water is one of the main improved water sources that plays an important role in achieving safely managed drinking water services [1]. In many developing countries, communitymanaged small-scale piped water supply systems are common, especially in rural areas, where public and private entities do not operate water supply systems [4-6]. Communitymanaged small-scale water supply systems could be sustainably operated with community participation and support through the collection of water tariffs and could be one of the potential instruments in meeting Goal 6 of the SDGs [4,7].

It is essential for any water entities, whether public, private or community-managed, to understand that the public's general perception of water is that it is a social good [8]. Customer satisfaction plays a significant role in maintaining balance between customers' demand and utility performance $[9,10]$. Furthermore, it is necessary to understand how well a utility is performing to identify and prioritize the areas for improvement [11,12]. However, information regarding the service levels, such as the supply continuity and supply volume, as well as customer satisfaction, of community-managed water supply 
systems is scarce. As a result, it is a challenge to illustrate the current status of these systems in most developing countries $[4,13]$.

Nepal, a developing country in Asia, has enshrined access to safe drinking water as a fundamental right of every citizen in its Constitution. After the enactment of the Water Resource Act 1992, the responsibility of water supply services moved from the central government to local communities [14]. Water Users and Sanitation Associations (WUSAs), one of the main water service providers managed by the community, are responsible for the planning, construction, operation, and management of water supply systems, with support from the government. The performance assessment data books published in 2014, 2015, and 2016 by the Ministry of Water Supply depict problems of WUSAs, such as variations in water supply hours, water consumption per capita, and non-revenue water (NRW) among the water service providers [15-17]. Whether these problems in WUSAs are exacerbating water supply inequality is also of great concern to the water supply managers and the responsible government ministries, which are charged with achieving equality in water supply as per Goal 6 of the SDGs.

Furthermore, restrictive situations, e.g., the COVID-19 pandemic, might further increase water supply inequalities. Thus, it is of substantial importance to analyze the impacts of COVID-19 on water consumption in order to understand psychological, social, and financial dynamics in communities [18]. Therefore, this study aimed to analyze the current service levels of community-managed water supply systems, i.e., WUSAs, in Nepal, in comparison with other water supply schemes; assess the inequality of water consumption within and between WUSAs; and identify the impact of the COVID-19 pandemic on water consumption and inequality.

The data reported in the performance assessment data books, the water consumption data provided by WUSAs, and the data obtained via the field survey were used in this study. The Lorenz curve and the Gini coefficient $(G)$ were used to analyze and compare water supply inequality [19].

\section{Materials and Methods}

\subsection{Water Supply in Nepal}

Nepal, officially the Federal Democratic Republic of Nepal, is a country located in South Asia, bordering China to the north and India to the east, west, and south. Nepal experiences four seasons: summer, autumn, winter, and spring. The country is mainly divided into three geographical regions: the Terai region $(60-610 \mathrm{~m})$, the hilly region $(610-4877 \mathrm{~m})$, and the mountain region (4877-8848 m). The geographical conditions are among the predominant factors determining the water supply sources in Nepal. In the mountainous and hilly areas, streams and springs are the main sources of water, whereas groundwater is the main source of water in the flat area of Terai (Figure 1).

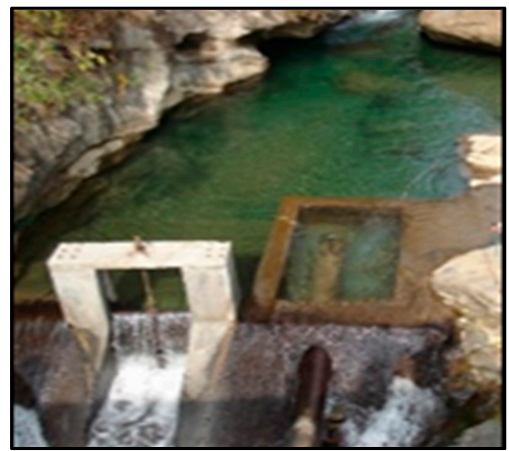

(a) ${ }^{1}$

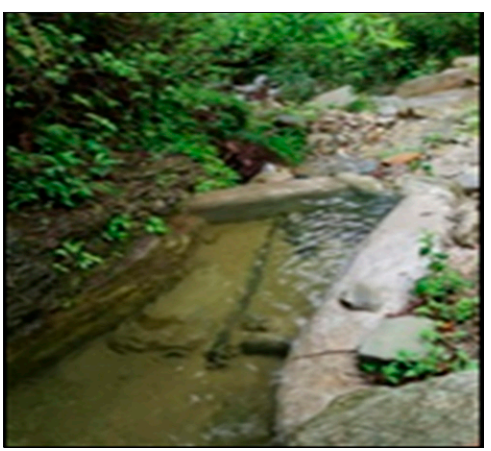

(b) 1

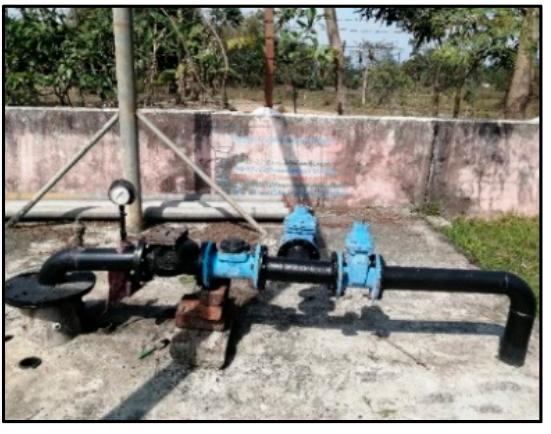

(c)

Figure 1. Major water sources in Nepal: (a) stream, (b) spring, and (c) deep tube-well. ${ }^{1}$ Source: Lekhnath Small Town Water Supply and Sanitation User Committee (LSTWSSUC). 
The Department of Water Supply and Sewerage Management (DWSSM), under the Ministry of Water Supply, was established in 1972 as the lead governmental agency for the water sector. There are three main types of water service providers in Nepal: Nepal Water Supply Corporations (NWSCs), Water Supply Management Boards (WSMBs) and Water Users and Sanitation Associations (WUSAs) (Table 1). NWSCs and WSMBs, primarily established to provide water supply in urban and municipal areas, are few in number throughout the country and cover limited areas. Moreover, with urbanization and amendment in urbanization criteria over time, the rural and semi-urban areas are emerging as urban and municipal areas. So, WUSAs, though initially centered on rural and semi-urban areas, also cover the areas that are not covered by NWSCs and WSMBs. The water supply service in Nepal is mainly categorized into three levels: basic, medium, and high level based on quantity, quality, accessibility and reliability (supply duration and continuity) (Table 2).

Table 1. Water service providers in Nepal.

\begin{tabular}{|c|c|c|c|}
\hline Water Service Provider & Governing Act & Service Area & Remarks \\
\hline $\begin{array}{l}\text { Nepal Water Supply } \\
\text { Corporation (NWSC) }\end{array}$ & $\begin{array}{l}\text { Nepal Water Supply } \\
\text { Corporation Act } 1989\end{array}$ & $\begin{array}{ll}- & \text { urban areas } \\
- & \text { amended as various areas } \\
& \text { (in 2010) }\end{array}$ & $\begin{array}{l}\text { - } \quad \text { autonomous government body } \\
\text { - } \quad 26 \text { offices }\end{array}$ \\
\hline $\begin{array}{l}\text { Water Supply } \\
\text { Management Board } \\
\text { (WSMB) }\end{array}$ & $\begin{array}{c}\text { Water Supply } \\
\text { Management Board Act } \\
2006\end{array}$ & municipal areas & $\begin{array}{l}\text { autonomous government body } \\
6 \text { offices }\end{array}$ \\
\hline $\begin{array}{c}\text { Water Users and } \\
\text { Sanitation Association } \\
\text { (WUSA) }\end{array}$ & Water Resource Act 1992 & $\begin{array}{ll}- & \text { rural and semi-urban areas } \\
\text { - } & \text { areas not covered by } \\
& \text { NWSCs and WSMBs }\end{array}$ & $\begin{array}{ll}- & \text { community-managed } \\
- & \approx 16,000 \text { WUSAs registered } \\
& \text { (others non-registered) }\end{array}$ \\
\hline
\end{tabular}

Table 2. Category of water supply services ${ }^{1}$.

\begin{tabular}{cccc}
\hline \multirow{2}{*}{ Service Indicators } & \multicolumn{3}{c}{ Service Levels } \\
\cline { 2 - 4 } & Basic & Medium & High \\
\hline Quantity (LPCD ${ }^{2}$ ) & $\geq 45$ & $\geq 65$ & $\geq 112$ \\
Quality & Potable & NDWQS, 2005 & NDWQS, 2005 ${ }^{3}$ \\
Accessibility & $\geq 75 \%$ customers (public tap) & $\geq 50 \%$ customers (private tap) & $\geq 75 \%$ customers (private tap) \\
Supply duration (hours/day) & $4-12$ & $12-18$ & $18-24$ \\
Continuity & Year-round (7-14 days & Year-round (7 days & Year-round \\
& interruption acceptable/year) & interruption acceptable/year) & \\
\hline
\end{tabular}

${ }^{1}$ As per National Urban Water Supply and Sanitation Sector Policy (NUWSSSP) 2014. ${ }^{2}$ LPCD = liters per capita per day. ${ }^{3}$ NDWQS $=$ National Drinking Water Quality Standards. ${ }^{4}$ Systems to be designed for $24 \mathrm{~h}$.

\subsection{Performance Assessment of Water Service Providers}

The Ministry of Water Supply published three performance assessment data books to assess the condition of the urban water supply managed by three types of water service providers (NWSCs, WSMBs, and WUSAs) in Nepal: Water Service Providers Data Book, 2069-2070 (2012-2013) in 2014, Nepal Water Service Providers Data Book, 2070-2071 (2013-2014) in 2015, and Water Service Providers Capacity Assessment and Benchmarking Data Year 2071-2072 (2014-2015) in 2016 [15-17]. The data books, which published performance indicator data of 77 water service providers (22 NWSCs, 3 WSMBs, and 52 WUSAs) selected from different regions of the country, were obtained and analyzed to identify the characteristics of WUSAs compared with the other two types of service providers.

\subsection{Selection of WUSAs}

Of the 77 water service providers, only 13 WUSAs have both water production and consumption recorded. Accordingly, five WUSAs were selected for the field survey based on the variation in water supply service (coverage, supply hours, and NRW), water source 
(surface water and groundwater), and different locations (province and geography). The selected WUSAs were Kakarvitta Water Users and Sanitation Association (KWUSA), Birat Water Supply and Sanitation Users Committee (BWSSUC), Khairenitar Small Town Water Supply and Sanitation Users Association (KSTWSSUA), Lekhnath Small Town Water Supply and Sanitation User Committee (LSTWSSUC), and Tulsipur Water Supply and Sanitation Users Association (TWSSUA) (Figure 2). Hereafter, these WUSAs are referred to by the initial word of their names for easier interpretation: namely, Kakarvitta, Birat, Khairenitar, Lekhnath and Tulsipur.

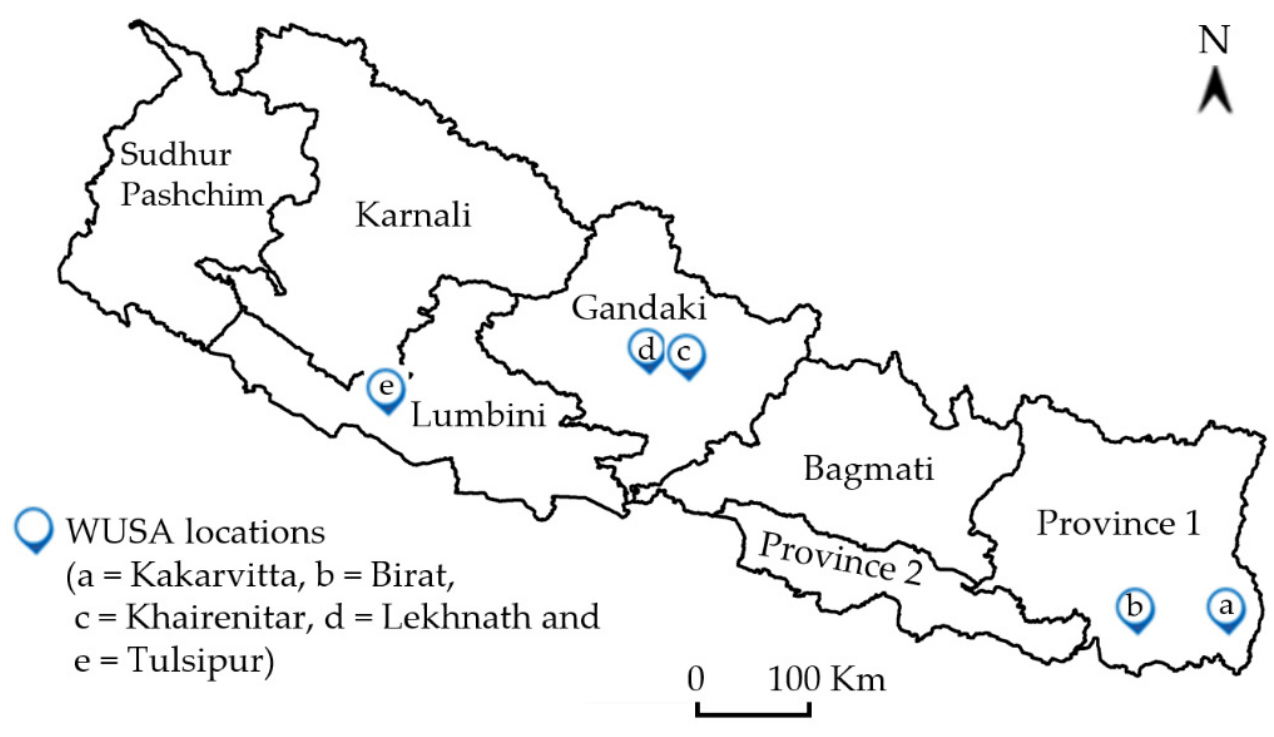

Figure 2. WUSA location in Nepal.

\subsection{Data Collection}

A field survey was carried out in February-March 2020 to examine the current water supply service conditions in the five WUSAs. It was found that each of the five WUSAs has cloud-based software for accounting and billing purposes. Kakarvitta uses the $\mathrm{H} 2 \mathrm{O}$ software, whereas the Metermark software is used by the other four WUSAs: Birat, Lekhnath, Khairenitar and Tulsipur. Mobile applications are used for customers' meter reading entries, which are later integrated into the billing software. Overall, the software integrates customers' water consumption data uploaded from meter readings, water tariffs, and bill payments, and makes it possible to access these data via the Internet.

\subsubsection{Water Pricing System}

The water tariff structure was obtained from three WUSAs; Birat, Lekhnath and Kakarvitta. Each of these WUSAs has an inclining block rates, in which water tariff remains constant for a certain minimum value, i.e., up to the first block, and then increases progressively as per the consumption volume.

\subsubsection{Bill Payment Data}

The data on water billing amounts and payments were obtained from Birat (two fiscal years' (FYs) data: FY 2018-2019 and FY 2019-2020) and Lekhnath (four FYs' data: FY 2016-2017 to FY 2019-2020). Both of the WUSAs have counter and online payment systems. Counter transactions mainly consist of water tariff payments and new connection fees, whereas online transactions are limited only to water tariff payments. The number of new connections was estimated from the increased number of customers in the monthly water consumption sheet. As customer ID was issued for each connection, the number of customers was the same as the number of connections. The new connection fees collected each month were calculated by multiplying the new connection fees per connection by the 
number of new connections. Then, the calculated new connection fees of each month were deducted from the total payments received at the counter to segregate the counter-collected water tariffs from the connection fees. The total tariffs collected were obtained from the summation of the water tariffs collected through the online and the counter systems.

\subsubsection{Customers' Water Consumption}

Anonymous data on individual customers' water consumption were obtained from three WUSAs, namely Birat (three years' data: FY 2017-2018 to FY 2019-2020), Lekhnath (five years' data: FY 2015-2016 to FY 2019-2020), and Kakarvitta (three years' data: FY 2017-2018 to FY 2019-2020). Customers were segregated based on their registration ID into: residential customers; health customers, such as hospitals or health centers; academic customers; business customers; social customers, such as youth clubs, welfare societies, or religious places; and office customers (Appendix A, Table A1). The customers were then coded based on the customer registration ID to further protect their privacy.

The customers were grouped into four categories: (a) all customers, from the obtained data sets, i.e., residential, health, academic, business, social, and office; (b) continuing customers, who had been customers in all of the study years, i.e., excluding new customers and terminated customers from the "all customers" category; (c) non-zero residential customers, which only included residential customers with at least $1 \mathrm{~m}^{3} /$ month water consumption; and (d) non-zero residential customers, with water consumption equal to or less than $50 \mathrm{~m}^{3} /$ month, to exclude large customers. The continuing customers were selected from all customers to exclude leaving or new customers during the study period, and non-zero residential customers were extracted from the continuing customers to exclude vacant or periodical-stay customers.

The numbers of total, continuing, non-zero residential customers, and non-zero residential customers with water consumption equal to or less than $50 \mathrm{~m}^{3} /$ month, were: 4655 , 3665, 3010 and 2235 for Birat (FY 2017-2018 to FY 2019-2020), 12,353, 8003, 5019 and 4057 for Lekhnath (FY 2015-2016 to FY 2019-2020), and 5796, 4640, 3319 and 2706 for Kakarvitta (FY 2017-2018 to FY 2019-2020), respectively.

\subsubsection{Customer Interview}

An anonymous customer interview was also carried out in February-March 2020 to assess the customers' acceptance and satisfaction levels. A total of 54 customers were interviewed: Kakarvitta, 12 customers; Birat, 10; Khairenitar, 10; Lekhnath, 11; and Tulsipur, 11. The type of water storage, overall satisfaction, and water supply duration were recorded.

\subsection{Data Analysis}

The collected data were statistically analyzed using R v.4.0.3 ( $\mathrm{R}$ core team, Vienna, Austria, 2014). As the latter half of July is the start of the FY in Nepal, July-August was taken as the beginning and June-July as the end of the FY for the analyses.

The main source of the WUSAs' revenue is water tariffs. Monthly billed amounts and collected tariffs were analyzed for all customers of Birat and Lekhnath to investigate cash flows and customers' preferences regarding the payment systems, i.e., counter or online. Similarly, block-wise distributions of water consumption and the number of customers for three FYs were examined for all customers in Birat, Lekhnath and Kakarvitta, based on the respective WUSAs' water pricing system.

The Shapiro-Wilk test was used to determine the normality in the yearly variation in water consumption data. The bootstrap method, which is a resampling technique with replacement, was used to estimate multiple-year water consumption variation among non-zero residential customers. For Birat and Kakarvitta, the consumption variation for three years, between FY 2017-2018 and FY 2019-2020, was estimated based upon similar variation for two years, between FY 2017-2018 and FY 2018-2019, to assess the consistency of the variation in water consumption. Similarly, for Lekhnath, the consumption variation 
for five years, between FY 2015-2016 and FY 2019-2020, was estimated based upon similar variation for two years, between FY 2015-2016 and FY 2016-2017.

The water supply duration in hours, reported in customer interviews, was plotted against the respective customers' water storage volume and satisfaction level. The Lorenz curve and Gini coefficient $(\mathrm{G})$ were used to assess the water consumption inequality among the customers, considering only non-zero residential customers with a water consumption equal to or less than $50 \mathrm{~m}^{3} /$ month. The proportionality of distribution is graphically and numerically represented by the Lorenz curve and the Gini coefficient, respectively. The Gini coefficient indicates variation in inequality distribution; $G=0$ for complete equality, $G=1$ for complete inequality, and $G \geq 0.40$ is the critical value [20]. The Gini coefficient is obtained by dividing the area between the Lorenz curve and line of equality by the total area below the line of equality.

\section{Results}

\subsection{Performance Assessment of Service Providers}

The minimum, maximum, and average values of performance indicators were calculated for the water service providers $(n=77)$ to compare the difference in the water service levels among the three types of service providers (Table 3). Overall, a high variation in water supply service levels was observed among the water service providers. The average water supply coverage was $72 \%$, with the minimum being $40 \%$ and the maximum being $96 \%$ for the WSMB, followed by WUSA 65\% (20-97\%) and NWSC $42 \%(14-98 \%)$. The lowest average service coverage of NWSCs is due to the presence of a large number of NWSCs with low coverage. In contrast, the water production per capita was the highest for NWSC at 140 LPCD (liters per capita per day) (74-255 LPCD), followed by WSMB (112 LPCD (56-161 LPCD)) and WUSA (89 LPCD (35-208 LPCD)). However, the average water consumption was not substantially different for NWSC (81 LPCD), WSMB (79 LPCD), and WUSA (70 LPCD) because the NRW rate was the highest for NWSC (39\%) and the lowest for WUSA (22\%). This means that the smaller system of water supply networks in WUSAs had more of an advantage in maintaining water leakage at lower levels than the larger systems, such as NWSCs and WSMBs. However, it should be noted that only 21 water service providers have metered water production, whereas 34 have fully metered connections to measure customers' water consumption. Only 13 WUSAs have both water production and consumption fully metered. Although the overall average NRW rate was reported to be $27 \%$, it should be noted that this percentage was calculated based on estimated values of the NRW rates due to the absence or malfunctioning of water meters.

The unit production cost was the lowest for WUSA $\left(10 \mathrm{NPR} / \mathrm{m}^{3}\right)$ compared to WSMB $\left(11 \mathrm{NPR} / \mathrm{m}^{3}\right)$ and NWSC $\left(13 \mathrm{NPR} / \mathrm{m}^{3}\right)$. In addition, the average water tariff, calculated from the ratio of total annual billing to total water consumption, was the highest for WUSA $\left(17 \mathrm{NPR} / \mathrm{m}^{3}\right)$ compared to NWSC $\left(14 \mathrm{NPR} / \mathrm{m}^{3}\right)$ and WSMB $\left(14 \mathrm{NPR} / \mathrm{m}^{3}\right)$. The overall average unit production cost was $11 \mathrm{NPR} / \mathrm{m}^{3}$, whereas the overall average water tariff was $16 \mathrm{NPR} / \mathrm{m}^{3}$. Typically, unit production costs only consisted of operating costs such as the cost of electricity, staff, transport, chemicals, repairs, and maintenance. The number of staff, type of system (gravity flow or pumping), chemicals, and transport usage may differ among water service providers. Therefore, the unit production cost varied more than 17 -fold from the minimum of $2 \mathrm{NPR} / \mathrm{m}^{3}$ to the maximum of $35 \mathrm{NPR} / \mathrm{m}^{3}$, and the average tariff varied more than 11 -fold from $4 \mathrm{NPR} / \mathrm{m}^{3}$ to $47 \mathrm{NPR} / \mathrm{m}^{3}$. These results indicate high variation in the financial status of the water service providers.

The operating ratio, which is defined as the ratio of operating expenses to revenue, was $86 \%$ for WUSA, $139 \%$ for NWSC, and $87 \%$ for WSMB. Although the average operating ratio for all service providers was 101\%, only 27 water service providers (WUSAs $=13$ and NWSCs $=14$ ) had operating ratios over $100 \%$, which indicates financial instability among the service providers. The bill collection rate, which is the ratio of payments collected to billing, was high, at $95 \%$ on average; and the highest was that of WUSA (99\%) followed by NWSC (87\%) and WSMB (87\%), which also indicates the advantage of small systems. The 
maximum bill collection rate of $130 \%$ was due to the payment of water bills pending from the previous FY. The average water supply hours were $10 \mathrm{~h} /$ day, with the longest supply hours for WUSA $(12 \mathrm{~h})$ followed by WSMB $(7 \mathrm{~h})$ and NWSC $(6 \mathrm{~h})$. The high variation in supply hours for WUSA, however, indicates that there are some WUSAs with 24 h supply, whereas others were as short as $1 \mathrm{~h}$ /day. On the contrary, this intermittent supply system is prevalent among the service providers of NWSC and WSMB.

Table 3. Performance assessment of service providers ${ }^{1}$.

\begin{tabular}{ccccc}
\hline Performance Indicators & $\begin{array}{c}\text { WUSA } \\
(\boldsymbol{n}=\mathbf{5 2})\end{array}$ & $\begin{array}{c}\text { NWSC } \\
(\boldsymbol{n}=\mathbf{2 2})\end{array}$ & $\begin{array}{c}\text { WSMB } \\
(\boldsymbol{n}=\mathbf{3})\end{array}$ & $\begin{array}{c}\text { Total } \\
(\boldsymbol{n}=\mathbf{7 7})\end{array}$ \\
\hline 1. Water supply coverage (\%) & $65(20-97)$ & $42(14-98)$ & $72(40-96)$ & $59(14-98)$ \\
2. Production/ capita (LPCD) & 89 & 140 & 112 & 104 \\
& $(35-208)$ & $(74-255)$ & $(56-161)$ & $(35-255)$ \\
3. Consumption/ capita (LPCD) & 70 & 81 & 79 & 73 \\
& $(27-181)$ & $(54-109)$ & $(43-108)$ & $(27-181)$ \\
4. Connections metered (\%) & 94 & 96 & 97 & 95 \\
5. NRW rate (\%) & $(0-100)$ & $(84-100)$ & $(93-100)$ & $(0-100)$ \\
6. Unit production cost (NPR/m $\left.{ }^{3}\right)^{2}$ & $22(4-51)$ & $39(12-65)$ & $29(25-33)$ & $27(4-65)$ \\
7. Average tariff (NPR/m $)^{2}$ & $10(3-35)$ & $13(2-24)$ & $11(7-18)$ & $11(2-35)$ \\
8. Operating ratio (\%) & $17(4-47)$ & $14(7-23)$ & $14(11-17)$ & $16(4-47)$ \\
& 86 & 1393 & 87 & 101 \\
9. Bill collection rate (\%) & $(44-167)$ & $(20-280)$ & $(70-100)$ & $(20-280)$ \\
10. Water supply (hours/day) & 99 & 87 & 87 & 95 \\
& $(75-130)$ & $(70-100)$ & $(70-100)$ & $(70-130)$ \\
\end{tabular}

${ }^{1}$ mean (minimum-maximum). ${ }^{2} 1 \mathrm{USD} \approx 115 \mathrm{NPR} .{ }^{3}$ High average operating ratio is due to presence of large numbers of NWSCs $(n=14)$ with high operating ratios $(>100 \%)$.

\subsection{Data Profile of Five WUSAs}

Table 4 shows the profile of the five WUSAs based on the data collected in the field survey. Although all of the five WUSAs have flow meters to measure water production, most of the flow meters were malfunctional, mainly due to a lack of maintenance and low quality materials. Only in Lekhnath were flow meters functional and was the daily water production recorded. Water production for the other four WUSAs was estimated based upon the reported discharge and operating hours. In Kharenitar, the online data integration process was in the initial phase and field meter readings were yet to be incorporated into the system. The NRW rates, calculated based on the estimated water production and billed metered consumption, were found to be $41 \%$ or higher for the WUSAs. These data are subject to change as more accurate production data may be obtained in future. Leakages in clear water tanks and distribution networks were reported by the WUSAs, which may be among the main reasons for the high NRW. The water supply hours of WUSAs ranged from 3 to $24 \mathrm{~h}$ per day. Limited water sources, size of the pipes, pressure distribution, unsystematic extensions, unequal water distribution, and technical skills/knowledge were reported as some of the many reasons for the variation in water supply hours. The number of staff seems to be influenced by service connections and number of systems in operation; Lekhnath serves more connections and Tulsipur has more water supply systems in operation. The clear water tank volume seems to be influenced by the number of connections; Khairenitar has the lowest number of connections $(n=1603)$ and the smallest water tank $\left(710 \mathrm{~m}^{3}\right)$ compared to Lekhnath, which has a water tank of $2100 \mathrm{~m}^{3}$ and the highest connection number of 12,110. Moreover, Tulsipur has the largest storage volume of $2301 \mathrm{~m}^{3}$, which may be due to the short water supply hours, because more water is required to supply all customers within limited supply hours. 
Table 4. Data profile of WUSAs (as per field survey in February-March 2020).

\begin{tabular}{cccccc}
\hline Description & Kakarvitta & Birat & Khairenitar & Lekhnath & Tulsipur \\
\hline${\text { Water production }\left(\mathrm{m}^{3} / \text { day) }\right.}^{1}$ & 7970 & 5400 & 1555 & 10,716 & 7085 \\
Water consumption (m $^{3} /$ day) & 3476 & 2672 & NA & 6335 & 3662 \\
NRW rate (\%) & 56 & 50 & NA & 41 & 52 \\
Water supply (hours/day) $_{\text {Staffs }}^{24}$ & 20 & 14 & $10-24$ & 14 & 3 \\
Number of connections & 5894 & 4651 & 14 & 34 & 27 \\
Clear water tank (m $^{3}$ ) & 1325 & 1025 & 710 & 2100 & 2301 \\
Water source $^{3}$ & GW & GW & GW, SW & GW, SW & GW, SW \\
Province & Province 1 & Province 1 & Gandaki & Gandaki & Lumbini \\
\hline
\end{tabular}

${ }^{1}$ Estimated from reported discharge and operating hours for Kakarvitta, Birat, Khairenitar and Tulsipur. ${ }^{2}$ Values for Kakarvitta, Birat, and Tulsipur were calculated based on estimated water production. NA = Not available. ${ }^{3} \mathrm{GW}=$ groundwater, $\mathrm{SW}=$ surface water.

\subsection{Water Tariff Payment}

A water tariff payment analysis was carried out for Birat and Lekhnath (Figure 3). Generally, March to May is spring, June to August is summer, September to November is autumn, and December to February is the winter season in Nepal. Both of the WUSAs showed similar seasonal variations in the billed amounts, which were low in the winter season (January-February) and high in the summer season (July-August) before MarchApril 2020, when the COVID-19 lockdown was imposed. In addition, the increasing trend of the billed amounts in Lekhnath has been obvious since 2016. In both WUSAs, online payment gradually increased until FY 2019-2020, and then almost stabilized. In Lekhnath, online payments surpassed counter payments in FY 2018-2019.

During the COVID-19 lockdown period between March and May 2020, the billed amounts increased in both WUSAs, which indicates that customers consumed more water while staying at home. However, there were big gaps between the billed amounts and payments in March-April and April-May, which indicates payment activities were affected by the COVID-19 pandemic lockdown. In both Birat and Lekhnath, tariff collection was significantly reduced during March-April and April-May 2020 because of the apparent reduction in both counter and online payments.

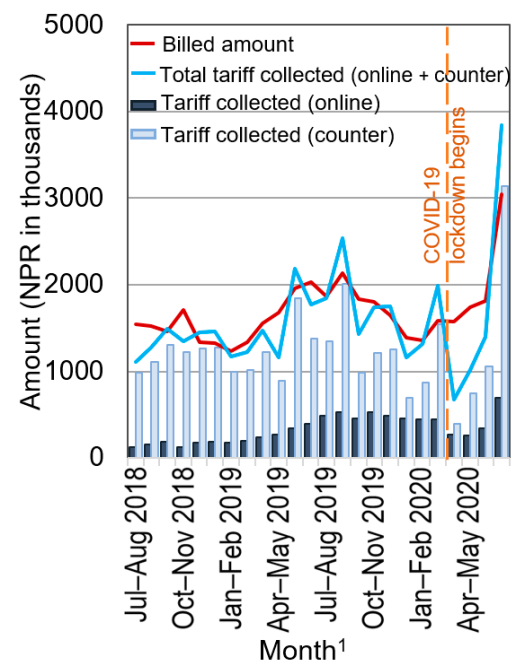

(a)

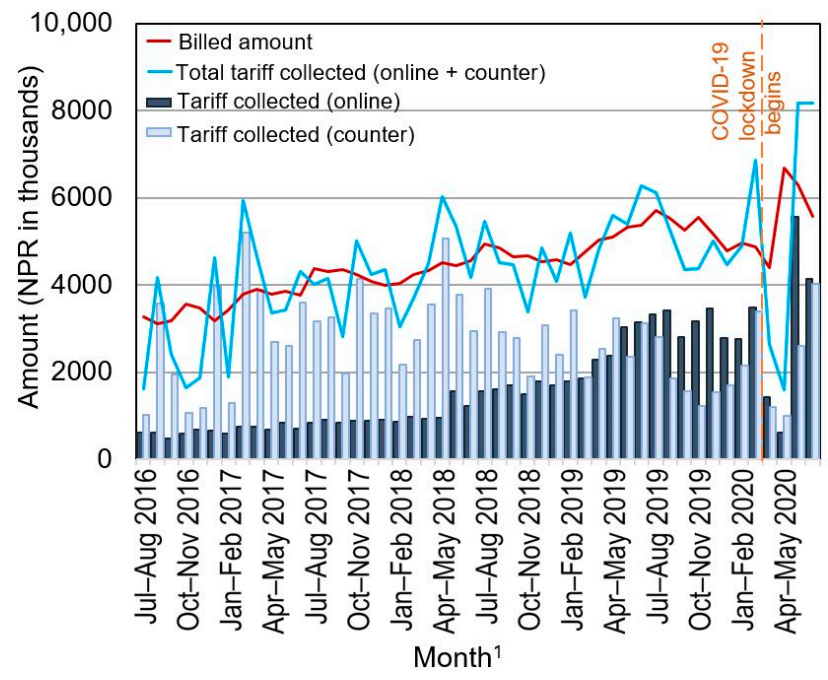

(b)

Figure 3. Payment activities ${ }^{2}$ : (a) Birat and (b) Lekhnath. ${ }^{1}$ Jul-Aug 2018: July to August 2018 corresponds to Shrawan, 2075 in Nepalese calendar (FY starts in Shrawan). ${ }^{2} 1$ USD $\approx 115$ NPR. 


\subsection{Block-Wise Distribution of Customers and Water Consumption}

The number of customers and water consumption based on the inclining block rates were analyzed for three FYs for all customers of Birat, Lekhnath and Kakarvitta; JulyAugust 2017 to June-July 2018, July-August 2018 to June-July 2019, and July-August 2019 to June-July 2020 (Figure 4). The water pricing systems for Birat, Lekhnath and Kakarvitta consist of seven blocks, four blocks, and seven blocks, respectively. The first block, which has a fixed charge, is lowest in Kakarvitta (NPR 70 for $5 \mathrm{~m}^{3}$ ), followed by Birat (NPR 90 for $6 \mathrm{~m}^{3}$ ) and Lekhnath (NPR 235 for $10 \mathrm{~m}^{3}$ ). However, Kakarvitta has classified blocks to a higher range above $100 \mathrm{~m}^{3}$, compared to Birat and Lekhnath, having the range classified as more than $35 \mathrm{~m}^{3}$ only.

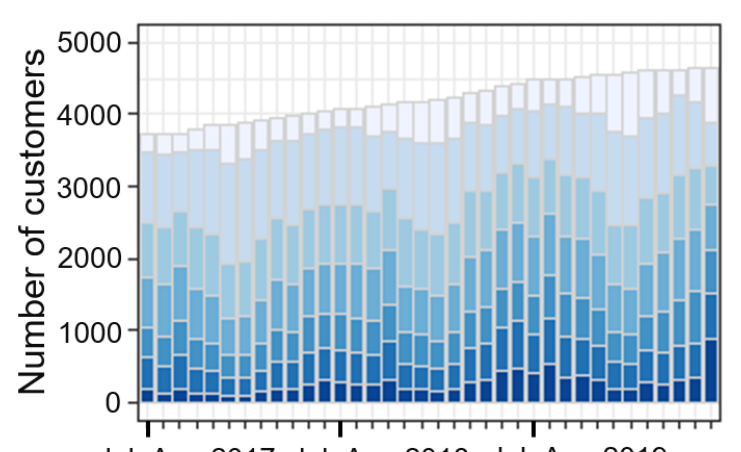

Jul-Aug 2017 Jul-Aug 2018 Jul-Aug 2019

Month
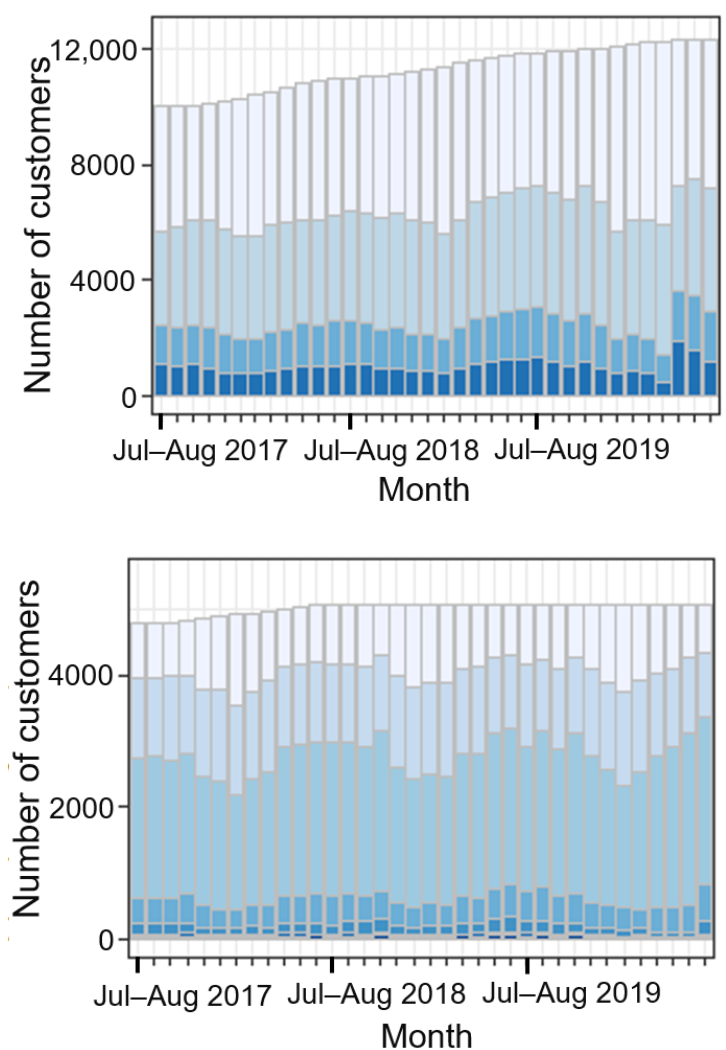

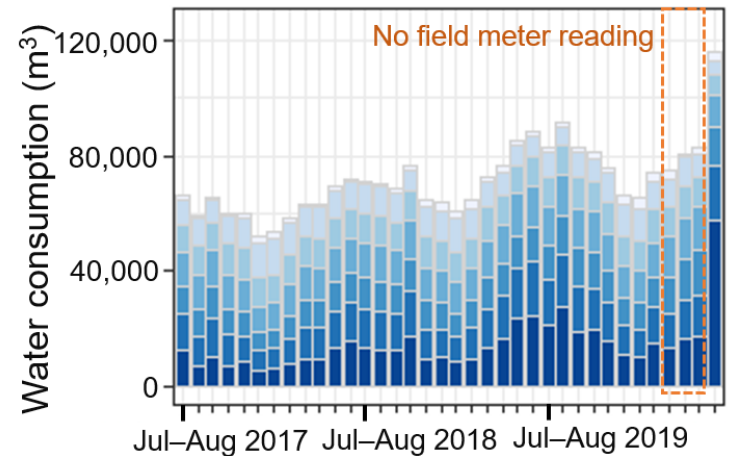

Month

(a)

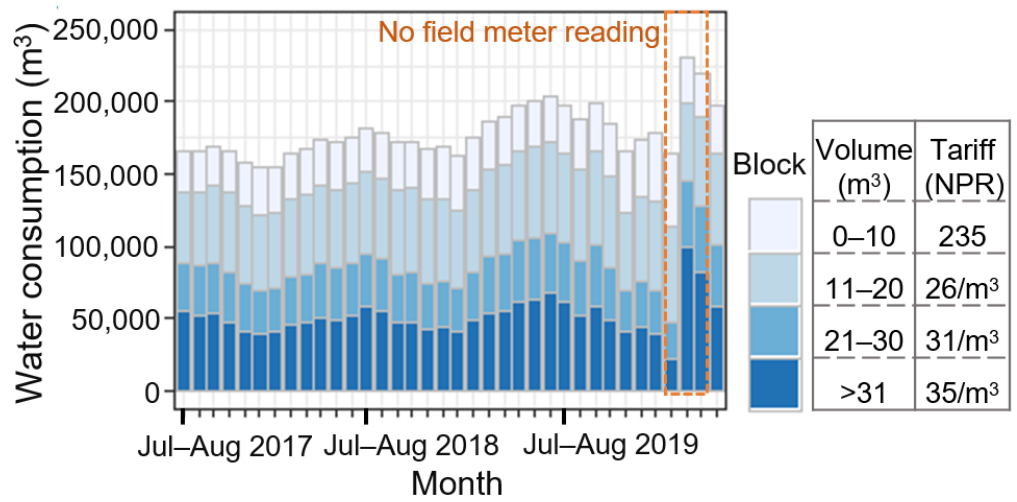

(b)

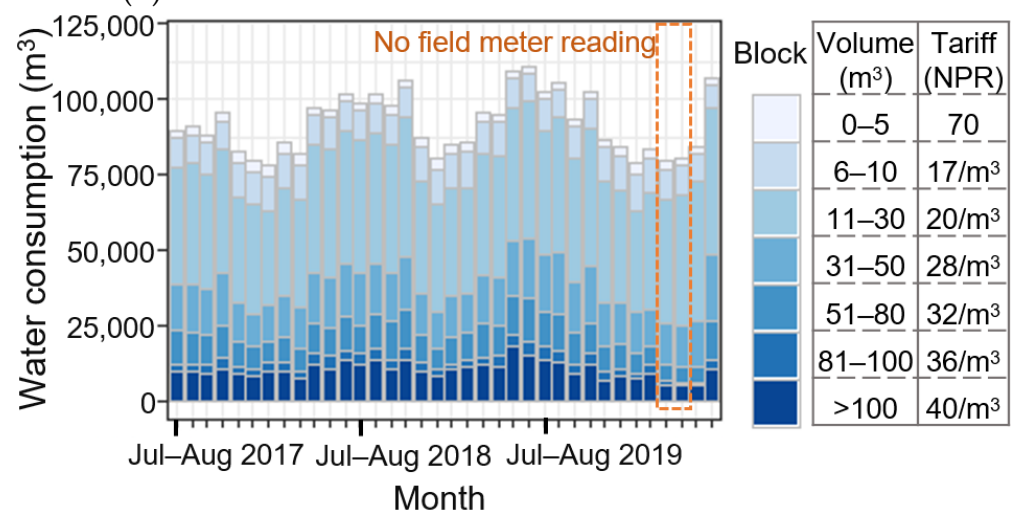

(c)

Figure 4. Customer numbers and water consumption distribution based on block tariff ${ }^{1}$ : (a) Birat ${ }^{2}$, (b) Lekhnath ${ }^{2}$, and (c) KWUSA ${ }^{2} .{ }^{1}$ As per FY $2019-2020$ tariff structure. 1 USD $\approx 115$ NPR. ${ }^{2}$ The height of each bar shows the total number of customers (left) and total water consumption (right) in each month, the color stack bars indicate those of the customers grouped by their monthly water consumption as shown in the legend. 
In Birat and Lekhnath, the numbers of customers were gradually increasing over the years, whereas, in Kakarvitta, although it increased initially, it subsequently appeared to remain constant. On average, the increasing rates of customers were calculated as $8 \%, 8 \%$, and $2 \%$ per year for Birat, Lekhnath and Kakarvitta, respectively. The lower growth rate in Kakarvitta may be due to their priority of maintaining $24 \mathrm{~h}$ supply rather than increasing the number of customers. The numbers of customers (Figure 4, left) and monthly water consumption (Figure 4, right) followed similar variation patterns over the years.

The nationwide lockdown, which started on 24 March 2020, restricted field meter readings in all three WUSAs. In Birat and Lekhnath, field meter readings were not taken for around three months (March-April 2020, April-May 2020, and May-June 2020), whereas, in Kakarvitta, readings were not taken for only around two months (March-April 2020 and April-May 2020). Customers' water consumption was estimated based on previous month consumption, manual approximations, and customers' phone call reporting in Birat and Lekhnath. However, in Birat, relatively high water consumption was observed when actual field meter reading was resumed in June-July 2020. This may be due to the underestimation of water consumption values in the preceding three months, which eventually accumulated in June-July 2020. In Lekhnath, water consumption appeared to be balanced out during the three months of estimation; in March-April 2020, the estimated water consumption was comparatively lower, and in April-May and May-June 2020 it was comparatively higher than usual patterns. Thus, when meter reading resumed in June-July 2020, a normal water consumption volume was observed.

On the contrary, Kakarvitta did not estimate the customers' water consumption volume prior to field meter readings due to the assumption that the actual water consumption may not match the estimated consumption, resulting in duplication of work. Thus, when field meter reading was resumed in May-June 2020, the obtained value was divided between the preceding halted months. The average water consumption for three months was observed to be lower than the water consumption in the same months of the preceding years.

\subsection{Consumption Variation within Customers}

The water consumption variation in non-zero residential customers, in terms of both percentage $(\%)$ and volume $\left(\mathrm{m}^{3}\right)$, were analyzed for Birat, Lekhnath and Kakarvitta, to determine the influence of small and large customers on the variation in water demands. The percentage changes in water consumption during the study period were high and similar among the three WUSAs (Figure 5). The customers who changed their water consumption by more than $10 \%, 20 \%$ and $50 \%$ were: $65 \%, 38 \%$, and $9 \%$ in Birat (variation average of two FYs), 63\%, 37\%, and 7\% in Lekhnath (variation average of four FYs), and $66 \%, 42 \%$ and $10 \%$ in Kakarvitta (variation average of two FYs), respectively.

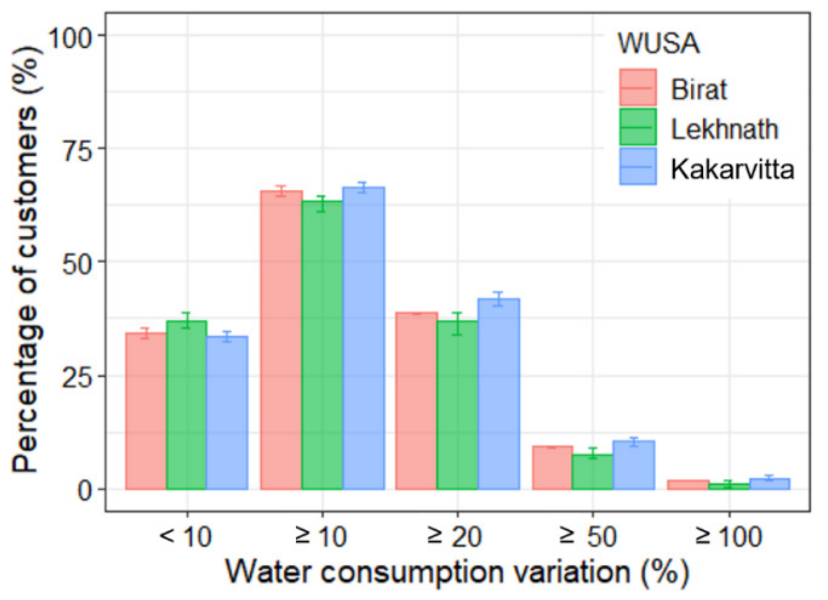

Figure 5. Proportion of customers with water consumption variation. 
In all WUSAs, the percentage of variation in the increase in water consumption was greater for small to medium customers (less than $300 \mathrm{~m}^{3}$ /year) than large customers (over $300 \mathrm{~m}^{3}$ /year), whereas the volume variation in increase was lower for small customers compared to medium and large customers (Figure 6). On the contrary, large customers appeared to decrease their water consumption, in both percentage and volume terms, compared to medium and small customers. These variations between FY 2018-2019 and FY 2019-2020 were also found in the variations between other years. Namely, the small customers slowly increased their water consumption, whereas large customers gradually decreased their water consumption over time. Overall, large variations in water consumption were observed among all customers.
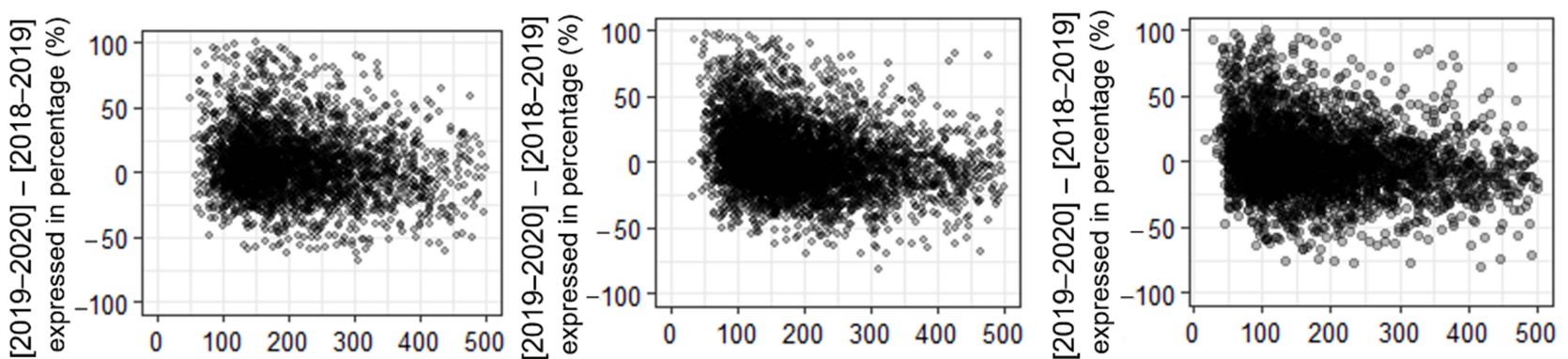

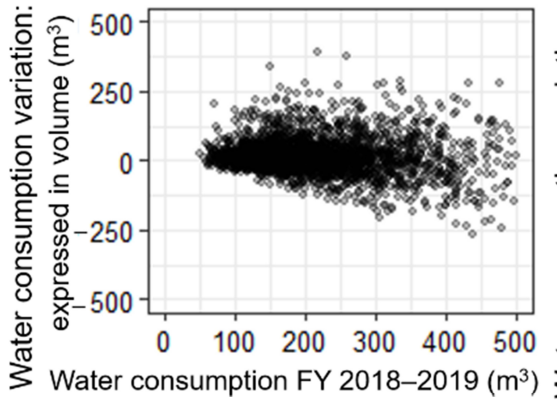

(a)

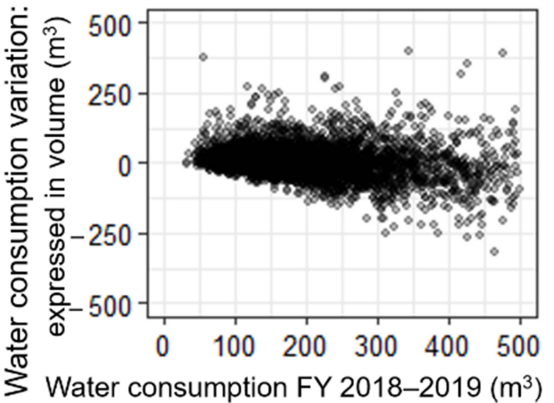

(b)

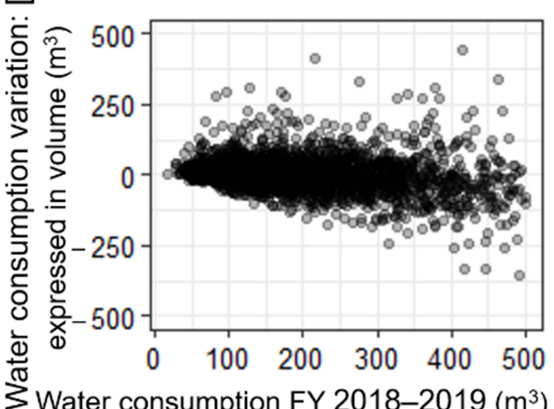

(c)

Figure 6. Water consumption variation among customers in percentage and volume terms: (a) Birat, (b) Lekhnath, and (c) Kakarvitta.

\subsection{Multiple-Year Water Consumption Variation}

To further examine the yearly variations in water consumption, histograms of water consumption variation $\left(\mathrm{m}^{3}\right)$ during the study period for non-zero residential customers were plotted: Birat for three years, Lekhnath for five years, and Kakarvitta for three years (Figure 7). The histogram of all the WUSAs indicates both an increase and a decrease in water consumption over the years. Moreover, the multiple-year water consumption variations were also estimated by using the bootstrap sampling method. In each of the WUSAs, water consumption variations were abnormally distributed (Shapiro-Wilk test: $p<0.05)$. The mean, median and standard deviations (SD) were calculated for Birat, Lekhnath and Kakarvitta (Table 5). The mean and median values were positive in all the WUSAs, with the mean values usually larger than the median values. In each of the three WUSAs, higher variance was observed in the estimated multi-year variations compared to the actual variations. 

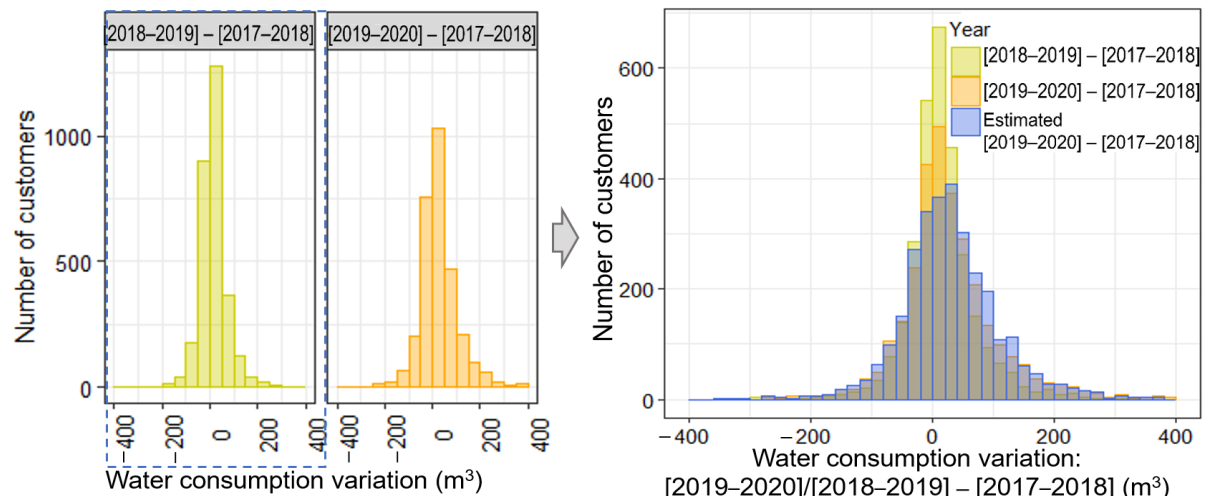

(a)
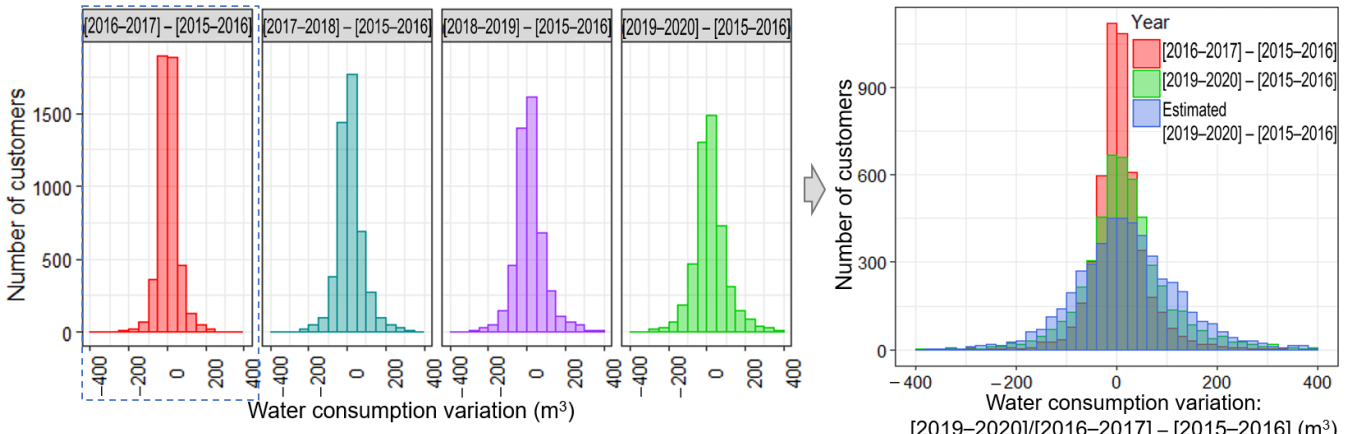

(b)
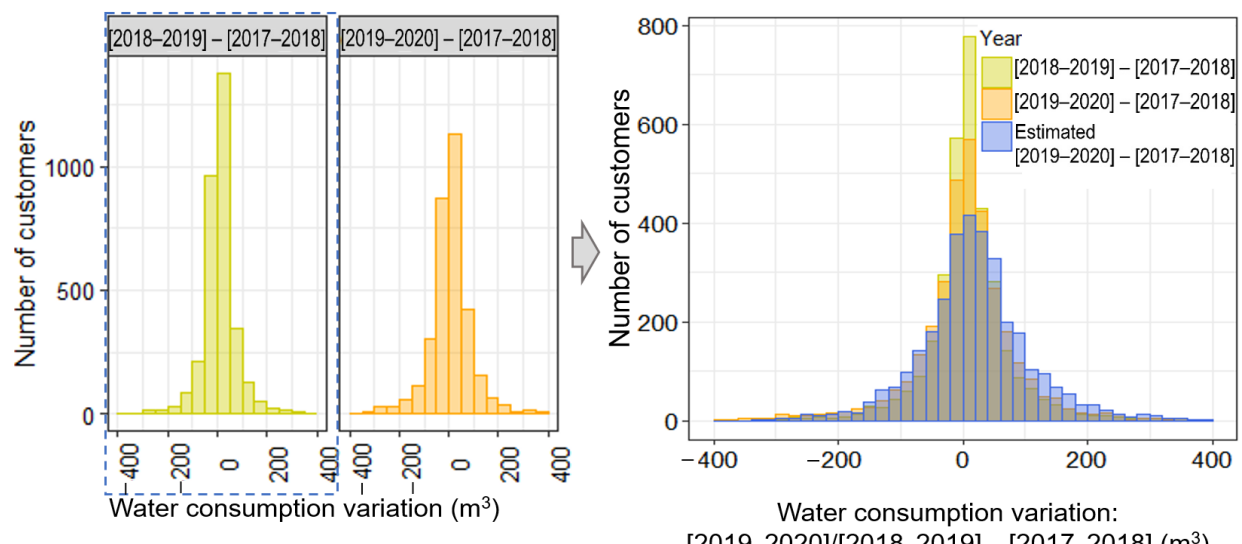

[2019-2020]/[2018-2019] - [2017-2018] $\left(\mathrm{m}^{3}\right)$

(c)

Figure 7. Multiple-year water consumption variation: (a) Birat, (b) Lekhnath, and (c) Kakarvitta.

Table 5. Variation in mean, median and standard deviation (SD) in WUSAs.

\begin{tabular}{ccccc}
\hline WUSA. & Fiscal Year (FY) & Mean $\left.\mathbf{( m}^{\mathbf{3}}\right)$ & Median $\left.\mathbf{( m}^{\mathbf{3}}\right)$ & SD \\
\hline \multirow{3}{*}{ Birat } & $(2018-2019)-(2017-2018)$ & 15.21 & 10.50 & 57.53 \\
& $(2019-2020)-(2017-2018)$ & 27.47 & 17.50 & 79.16 \\
& Estimated (2019-2020)-(2017-2018) & 31.58 & 25.00 & 82.00 \\
\hline \multirow{4}{*}{ Lekhnath } & $(2016-2017)-(2015-2016)$ & 5.18 & 2.00 & 54.02 \\
& $(2017-2018)-(2015-2016)$ & 16.85 & 11.00 & 69.96 \\
& $(2018-2019)-(2015-2016)$ & 14.76 & 9.00 & 79.02 \\
& $(2019-2020)-(2015-2016)$ & 17.18 & 11.00 & 86.20 \\
Kakarvitta & Estimated (2019-2020)-(2015-2016) & 21.46 & 17.00 & 106.94 \\
& $(2018-2019)-(2017-2018)$ & 10.14 & 8.00 & 67.24 \\
& Estimated (2019-2020)-(2017-2018) & 20.18 & 8.00 & 83.32 \\
& & & 17.00 & 90.93 \\
\hline
\end{tabular}




\subsection{Inequality of Water Consumption}

3.7.1. Intermittency in Water Supply

From the customer interviews carried out in the five WUSAs, customers with access to $24 \mathrm{~h}$ supply mostly had no water tanks or only small ones, whereas customers with access to a water supply for only few hours a day had relatively larger water tanks (Figure 8a). The large water tanks were usually underground. The cost of pumping water from the underground tanks can be considered as an additional cost to the customers, in addition to water tariffs. Moreover, variations in customer responses were observed between and within WUSAs. Usually, customers with more supply hours reported higher satisfaction compared to customers with a shorter water supply duration. This appeared to be reflected in the high satisfaction of customers who received water $24 \mathrm{~h} /$ day, i.e., $168 \mathrm{~h} /$ week. However, customers with shorter water supply hours also reported high satisfaction levels if the water supply time was regular during the peak demand hours (Figure $8 \mathrm{~b}$ ). It appeared that, if the water supply hours were reduced below $25 \mathrm{~h}$ /week, i.e., $3.5 \mathrm{~h} /$ day, then the customer satisfaction also decreased due to the short supply hours. Customers with a longer supply duration reported water quality problems and tariff issues (Figure $8 \mathbf{b}$ ). As the customers had little or no knowledge of chemical and biological water quality parameters, they were more concerned about the physical characteristics of the water, such as turbidity and chlorine smell. In general, customers preferred water with a clean appearance. Therefore, customer satisfaction was reported to be affected not only by one factor, but by multiple factors, such as water supply duration, time, quality, and tariff.

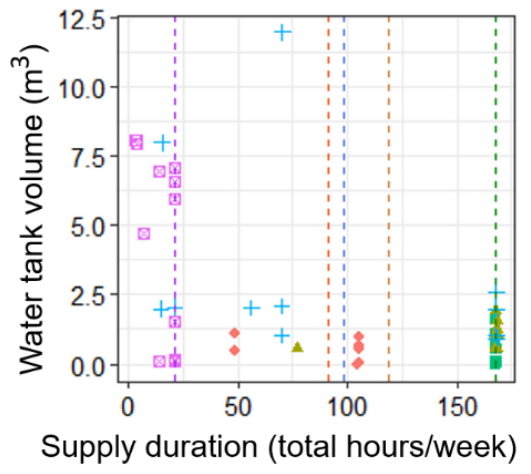

(a)

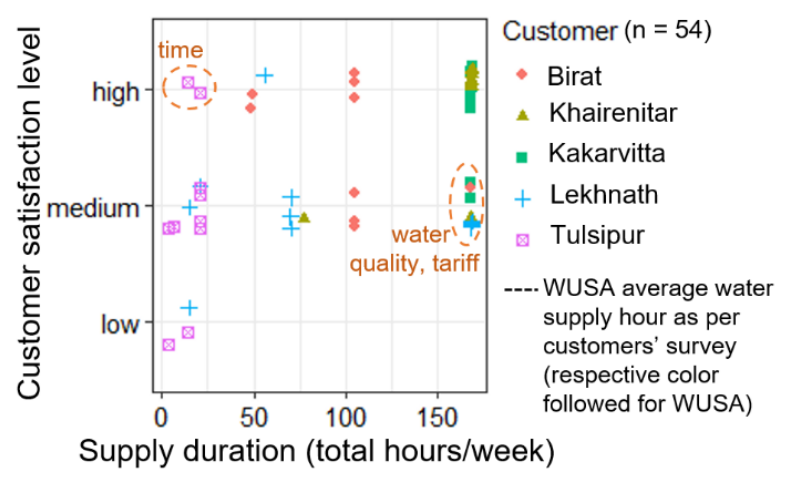

(b)

Figure 8. Water supply duration versus customers' ${ }^{1}$ : (a) water storage tank volume and (b) satisfaction level. ${ }^{1}$ Each dot (shape) represents a response, and the dots are jittered to prevent overlapped plotting.

\subsubsection{Gini Coefficient of Water Consumption Volume}

The yearly water consumption of non-zero residential customers with a water consumption equal to or less than $50 \mathrm{~m}^{3} /$ month was examined using the Lorenz curve and Gini coefficient (Figure 9). In all WUSAs, the Gini coefficient $(G)$ was below the critical value of 0.40; Birat $G=0.202-0.213$ (three years), Lekhnath $G=0.223-0.230$ (five years), and Kakarvitta $G=0.279-0.287$ (three years). The Gini coefficients were consistent during the study period in each of the three WUSAs. These results were represented by the almost overlapping Lorenz curves of the three WUSAs in each of the considered years, and the curves for Kakarvitta were more bowed compared to those for Birat and Lekhnath. 

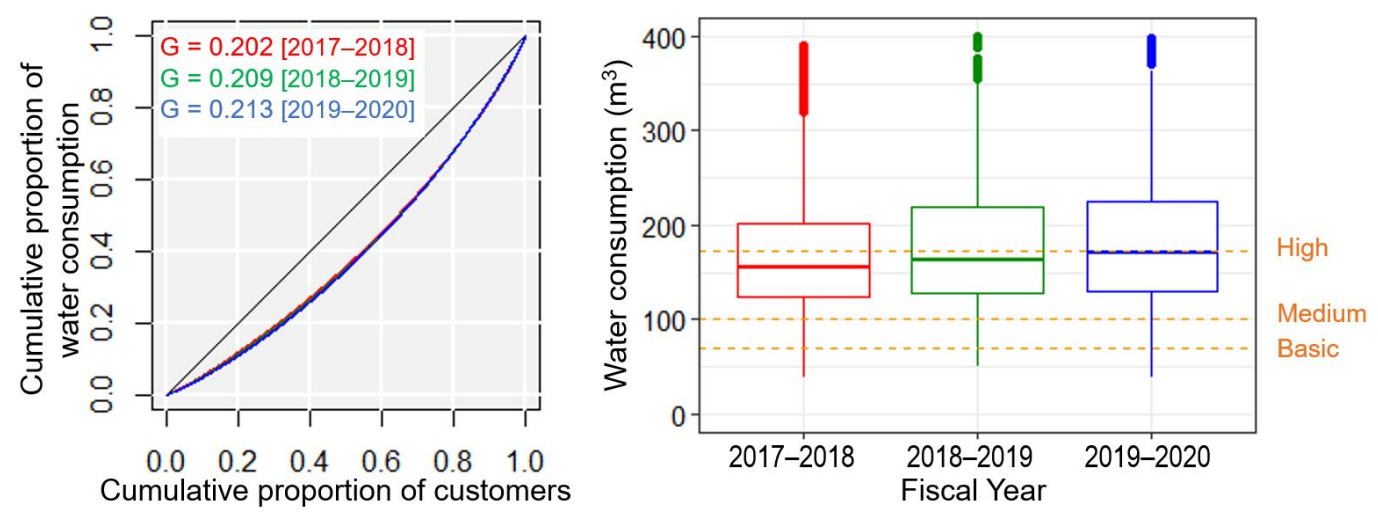

(a)
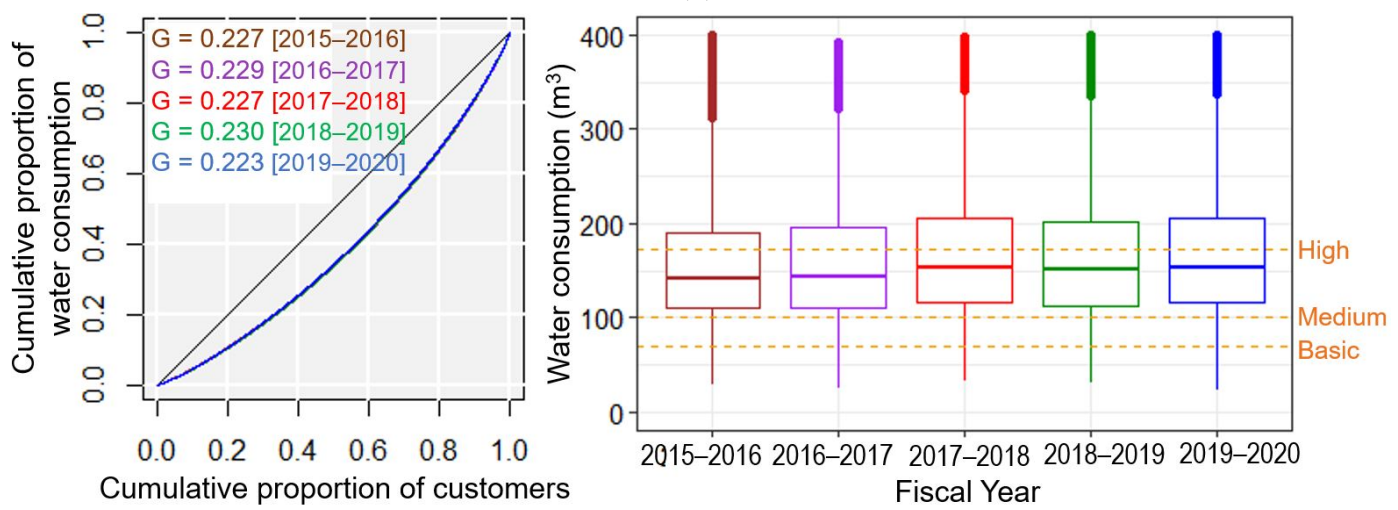

(b)
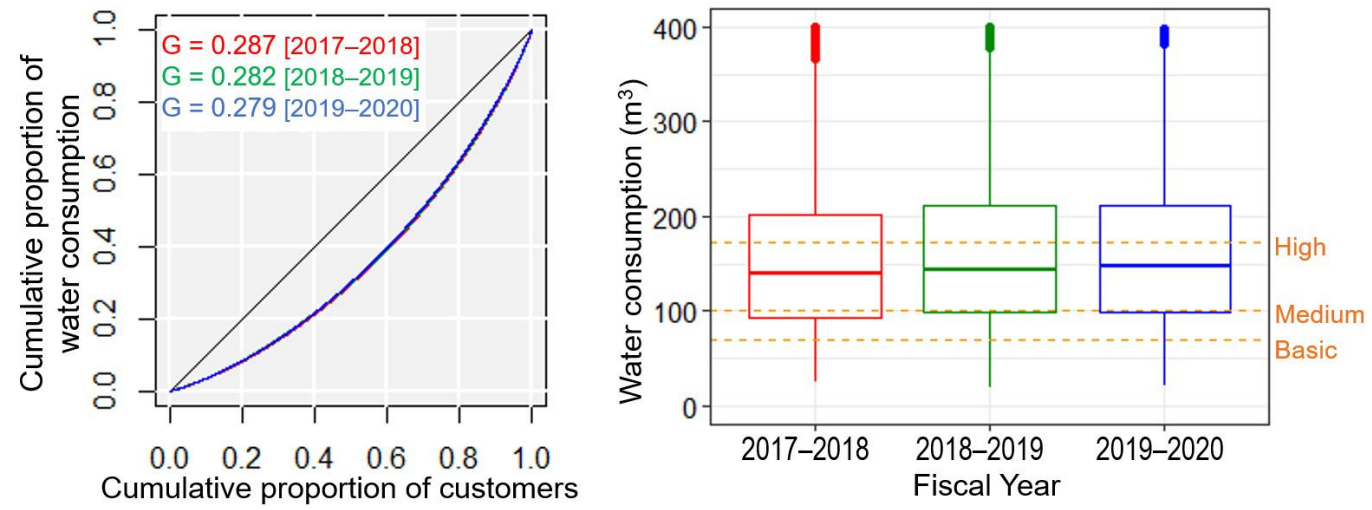

(c)

Figure 9. Lorenz curve (left) and volume (right) of yearly consumption: (a) Birat, (b) Lekhnath, and (c) Kakarvitta.

The customers' yearly water consumption volume slowly increased during the study period; Birat's three years (mean $=169.7-184.1$, and median $=155.0-171.3$ ), Lekhnath's five years (mean $=156.8-167.5$, and median $=142.0-155.0)$, and Kakarvitta's three years $($ mean $=156.8-165.1$, and median $=140.0-148.0)$. Considering the average household size of 4.2 for urban areas, minimum water consumption amounts of $68.98,99.64$, and $171.69 \mathrm{~m}^{3}$ per year correspond to meeting basic, medium, and high quantity service levels, respectively [21]. As a share of the total, customers with a water consumption below the basic volume of $68.98 \mathrm{~m}^{3}$ /year accounted for less than $1 \%, 3 \%$, and $10 \%$, and above the medium volume of $99.64 \mathrm{~m}^{3}$ /year, which accounted for more than $92 \%, 85 \%$ and $74 \%$, in Birat, Lekhnath and Kakarvitta, respectively. Moreover, customers with a water consumption above $171.69 \mathrm{~m}^{3}$ /year accounted for more than $45 \%, 38 \%$, and $38 \%$ of the total in Birat, Lekhnath and Kakarvitta, respectively. Despite the intermittency of supply, customers of Birat and Lekhnath were able to consume a similar or higher volume of water to those of Kakarvitta. 


\section{Discussion}

\subsection{Performance of Service Providers}

Based on the above comparison of the performance indicator values (Table 3), it can be said that WUSA was superior to NWSC and WSMB for indicator values such as low NRW, low production costs, high bill collection rate, and long water supply hours. Per capita water production was less for WUSA than other providers because of lower NRW rates and per capita water consumption. Thus, it can be said that contrary to our assumption, WUSA performs better than NWSC and WSMB, possibly because of the ease of operation and management, despite limited knowledge and expertise in the operation and maintenance of water supply systems. As the water demand is smaller than that of the large systems, WUSAs can easily find water resources to meet the water demand, making it possible for them to supply water over a $24 \mathrm{~h}$ period. Similarly, leakage detection and control may be easier for small systems than large systems. The high rate of bill collection is achieved due to the high rate of customer satisfaction in terms of water supply quantity [9], as described in the following section.

However, it should also be noted that the variation in the indicator values for WUSAs was the highest for five indicators, namely consumption per capita, metered connection, unit production cost, average tariff, and supply hours, among the three types of providers. Due to the limited financial and human resources for small water supply systems such as WUSAs, there is a high variation in the service levels of the small providers. As water tariff is the main revenue source, proper water pricing systems and optimization of resources may be essential to maintain a sound financial system, as well as for environmental sustainability [22-24]. Moreover, as most of the flow meters were reported malfunctioning during the field survey, provision of good quality flow meters and proper maintenance is needed to maintain higher accuracy of NRW records, which eventually helps service providers to prioritize and upgrade the systems so as to reduce economic losses and conserve water resources [25-28].

\subsection{Payment Activities}

Payment activities are substantial to water service providers as they are related to the amount and timing of cash-flow, and they eventually affect the providers' ability to meet financial obligations [9]. The billed amounts over the years, in Birat and Lekhnath, illustrate the changes in revenue generation with seasonal variation, suggesting fluctuation in water consumption with seasons (Figure 3). The payment activities analysis for both the WUSAs showed that the online payments were more consistent, with few fluctuations. However, the amounts of the counter payments varied extensively in both WUSAs. This means that customers do not go to pay their water tariff every month, but do go to a counter once every few months to pay their accumulated water bills. Therefore, the total payment was influenced by counter payments and fluctuated extensively in the past. These results revealed that online payments are more convenient than counter payments, making bill collections more stable each month. Moreover, the tariffs collected from online payments with respect to the total collected tariffs for the last FY (from July-August 2019 to June-July 2020) was found to be $26 \%$ for Birat and $60 \%$ for Lekhnath. This is much higher than the findings in some of the water utilities in East and West Africa, where online payment adoption rates of $1-10 \%$ were observed $[29,30]$. This indicates more willingness to use online payments among the people of Nepal, which suggests that an increment in online payment could be achieved in future with more advertisement of the online payment solutions by the water service providers.

During the lockdown period, although it is understandable that counter payment decreased, it is interesting to note that online payment also decreased significantly. This might be because customers tend to withhold any payments under unknown and uncertain conditions, due to a mindset of preparing for a more serious situation. This might be supported by the fact that the Gross Domestic Product, with a growth rate of 7\% in FY 2019, contracted to $-1.9 \%$ in FY 2020, indicating a squeeze in job opportunities [31]. However, 
after the lockdown, both counter and online payments increased extensively because customers paid their bills for the lockdown period, which suggests uncertainties among customers was mainly due to the restricted situation.

\subsection{Block-Wise Water Consumption}

As the lower blocks have comparatively low water tariff rates compared to the higher blocks, it can be considered as a kind of cross subsidy; the high-volume customers support the low-volume customers (the legend in Figure 4). When block-wise distribution is considered, we can see that there was a larger number of customers in blocks of lower consumption volume compared to higher volume blocks. Moreover, the number of highvolume block customers appeared to increase in summer compared to winter, indicating the influence of seasonal variation. As well as to the number of customers, the monthly water consumption slowly increased in each of the three WUSAs. As the fluctuations in the block-wise customers were observed, the water consumption patterns also depicted seasonal variations. This may be due to more frequent water consumption activities such as showering and washing during summer [32].

In general, water consumption appeared to follow a similar pattern in each year. However, a different pattern was observed from March-April 2020, the month when the nationwide lockdown was imposed due to the COVID-19 pandemic. Based on these water consumption data, the monthly water consumption volume appeared to increase during the COVID-19 pandemic lockdown in Birat and Lekhnath. As per the information from the two WUSAs, this may be mainly due to an increase in residential water usage, because more people stayed at home and consumed more water for indoor activities such as personal hygiene and cooking, which is similar to previous studies in California and England [33,34]. However, this was not in the case of Kakarvitta; water consumption decreased during the lockdown period compared to the same month of the preceding year. Kakarvitta's service area is one of the main gateways to India, and its economy is normally supported by commercial activities. However, these commercial activities were restricted during the pandemic lockdown, which may have reduced water consumption compared to that of previous years. Similar results were reported in two Apulian towns in Italy and in southern Brazil $[18,35]$. Thus, the change in water consumption in the WUSAs appears to be influenced by indoor activities such as personal hygiene and cooking, in addition to commercial activities based on the local scenario.

\subsection{Water Consumption Variation}

High variations in yearly water consumption were observed in all the three WUSAs, which indicates that the number of persons in houses changed between the years because of study, business, or family issues (Figures 5 and 6). However, it should also be noted that, when the water consumption of all customers was calculated for each WUSA, the large variations in the yearly water consumption of each customer were cancelled out, and we can see only an overall trend of a gradual increase and seasonal variations in water consumption. This indicates that the yearly variation in water consumption by each customer took place due to their own reasons, rather than reasons that influenced all of the customers of each WUSA. Overall, large variations in water consumption were observed among all customers.

Moreover, the positive mean and median values, obtained from the multiple-year water consumption analysis of the WUSAs (Table 5) also indicate that the water consumption increased gradually, and the fact that the mean value is larger than the median value indicates that there are customers who substantially increased their water consumption from the previous year, which increased the mean values. Moreover, the peaks of two-year variation were high and near the mean values for the WUSAs, which gradually decreased and became broader with greater variance over multiple-year variations (Figure 7). The differences in the variance between the actual and estimated water consumption changes appeared to be greater with longer periods of estimation, i.e., five-year vs. three-year, which 
implied that the consumers who increased their water consumption in one year had a tendency to decrease their water consumption the following year, while water consumption increased overall.

\subsection{Inequality Analysis}

The customers consuming below the basic volume of $68.98 \mathrm{~m}^{3} /$ year accounted for less than $10 \%$, whereas above medium volume of $99.64 \mathrm{~m}^{3} /$ year and high volume of $171.69 \mathrm{~m}^{3}$ /year accounted for more than $74 \%$ and $38 \%$ of all customers, respectively in the three WUSAs: Birat, Lekhnath and Kakarvitta. Despite the variation in water supply hours among the three WUSAs, the water consumption distribution, as shown by the Lorenz curves and box plots (Figure 9), exhibited similar inequality and consumption amounts. Although these differences were not significant, the supply service levels in terms of water consumption amounts and equality appeared to be higher for Birat, followed by Lekhnath and Kakarvitta. However, this result does not agree with the supply hours, because Kakarvitta had a continuous mode of supply, i.e., $24 \mathrm{~h} /$ day, whereas both Birat and Lekhnath operate with an intermittent supply of $14 \mathrm{~h} /$ day. Hence, it can be concluded that the differences in the consumption volumes and Gini coefficients were not caused by differences in supply hours, but by other factors such as lifestyles, the number of persons in a house, house types, and the purposes of water use [27]. Moreover, water was usually supplied near the peak demand time and customers owned larger water storage tanks, which may have increased their capacity to cope with intermittent water supply $[36,37]$. The results of the customer survey (Figure 8) illustrated the influence of water supply hours on satisfaction level, because customers with a longer water supply duration were observed to have a higher satisfaction level compared to customers with a short water supply duration: satisfaction level for Kakarvitta (24 h/day) $>$ Khairenitar (11-24 h/day) $>$ Birat (7-15 h/day) $>$ Lekhnath (2-24 h/day) > Tulsipur (1-3 h/day). Thus, although customers coped with short supply hours by storing water in their tanks, their satisfaction was lower when they experienced shorter supply hours. Overall, the results of the inequality analysis indicate that, despite being a community-based small-scale water supply, the three WUSAs offered water supply services with sufficient amounts of water and low inequality regarding access to water. The Gini coefficients were observed to be significantly less than those reported for Kathmandu, the most populous city of Nepal, which were over 0.67 for water supply hours [19]. Although high inequality in terms of water supply hours has been reported in the Kathmandu Valley, the results of this study suggest better service levels can be achieved with lower levels of inequality in small-scale water supply systems than in large systems, such as the water supply in the Kathmandu Valley.

\section{Conclusions}

Based on our analysis of the performance indicators, it was revealed that the communitymanaged water supply providers, i.e., WUSAs, performed better than the large-scale providers, i.e., NWSCs and WSMBs, in terms of parameters such as low NRW rates and production costs, high bill collection rates, and long supply hours. However, a high variation in water supply service levels was also observed among WUSAs, which may be due to limited financial resources and technical skills/knowledge; malfunctional flow meters was reported as one of the common maintenance issues. Therefore, it can be said that, although WUSAs have significant potential to provide a high level of water supply services, the causes and factors influencing the performance of WUSAs should be further investigated to support WUSAs with low performance indicators.

Both the billed amount and monthly water consumption analysis indicate the influence of seasonal variations in water consumption patterns. In Birat and Lekhnath, the customers gradually shifted from counter payments to online payments when making their water tariff payments. The online payments were more consistent than the counter payments. Field meter readings and tariff payment activities were significantly affected by the COVID19 pandemic. Although water consumption increased in Birat and Lekhnath during 
the COVID-19 lockdown period, both online and counter payments decreased during the COVID-19 lockdown, possibly due to the limitations regarding movement and the customers' desire to avoid expenditure in order to prepare for even worse situations. On the contrary, water consumption decreased in Kakarvitta during the lockdown, possibly due to the reduction in commercial activities.

Generally, the annual water consumption increased in each of the three WUSAs, Birat, Lekhnath and Kakarvitta, as shown by the positive mean and median values of the water consumption changes during the study period. The increasing variance in this period indicates that the water consumption variations among the customers also widened. The changes in the water consumption of each customer between the years were high: $65 \%$, $39 \%$ and $9 \%$ of the customers changed their water consumption by more than $10 \%, 20 \%$ and $50 \%$, respectively, based on an average of three WUSAs. These high variations in water consumption volume may be due to changes in the number of family members living in each residence. Small to medium customers tended to increase their water consumption, whereas large customers tended to decrease their water consumption.

The Gini coefficients were consistent during the study period for each of the three WUSAs: Birat $\approx 0.20$, Lekhnath $\approx 0.23$, and Kakarvitta $\approx 0.28$. More than two-thirds of customers consumed water above the medium volume of $99.64 \mathrm{~m}^{3} /$ customer/year, and those consuming below the basic volume of $68.98 \mathrm{~m}^{3} /$ customer/year accounted for less than $10 \%$ of all consumers. The customer interviews indicated that most customers were satisfied with their supply volume, with large water tanks used as coping strategies for intermittent supply. Although these results indicate that most of the customers could afford water tariffs, water pricing among WUSAs should be further analyzed to assess its impact on customers' affordability and satisfaction, whilst maintaining financial stability.

This study indicates that the use of online software by WUSAs is very useful not only to record data regarding customers' water consumption and payments, but also with regard to research and data analysis, as undertaken in this study. The inequality in water consumption among customers was low, even under conditions of intermittent water supply, if sufficient water was regularly supplied and customers could store an adequate volume of water in storage tanks. Moreover, small water supply systems appear to have the potential to provide better and more equal water supply services compared to large cities, provided that their service levels are maintained at high levels with sufficient income and technical skills. Thus, providing assistance to maintain high service levels of WUSA is instrumental to achieve Goal 6 of the SDGs.

Author Contributions: Conceptualization, S.T., A.S. and S.K.; methodology, S.K. and S.T.; data analysis, A.S., S.K. and S.T.; investigation, A.S.; data curation, A.S. and S.K.; writing—original draft preparation, A.S.; writing - review and editing, S.T. and S.K.; visualization, A.S.; supervision, S.T. and S.K.; project administration, S.K. and S.T.; funding acquisition, S.T. All authors have read and agreed to the published version of the manuscript.

Funding: This research was funded by Japan International Cooperation Agency (JICA) though the collaborative program with the University of Tokyo and the scholarship provided to Arati Shrestha for her graduate studies.

Institutional Review Board Statement: Not applicable.

Informed Consent Statement: Not applicable.

Data Availability Statement: No new data were created or analyzed in this study. Data sharing is not applicable to this article.

Acknowledgments: The authors would like to express their gratitude to Lekhnath Small Town Water Supply and Sanitation Users Committee (LSTWSSUC), Birat Water Supply and Sanitation Users Committee (BWSSUC), Kakarvitta Water Users and Sanitation Association (KWUSA), Tulsipur Water Supply and Sanitation Users Association (TWSSUA), and Khairenitar Small Town Water Supply and Sanitation Association (KSTWSSUA).

Conflicts of Interest: The authors declare no conflict of interest. 


\section{Appendix A}

Table A1. Customers' category details.

\begin{tabular}{|c|c|c|c|}
\hline Category & Birat & Lekhnath & Kakarvitta \\
\hline & \multicolumn{3}{|c|}{ All of the customers until FY 2019-2020 are included. } \\
\hline All customers & $\begin{array}{l}4655 \text { (residential }= \\
4596, \text { social }=22, \\
\text { academic }=15, \\
\text { business }=11, \text { and } \\
\text { office }=11)\end{array}$ & $\begin{array}{c}12,353 \text { (residential }= \\
12,144, \text { social }=68 \\
\text { academic }=59 \\
\text { business }=53, \text { office }= \\
21, \text { and health }=8)\end{array}$ & $\begin{array}{c}5796 \text { (residential }= \\
5658, \text { social }=57 \\
\text { academic }=21 \\
\text { business }=17, \text { office }= \\
36, \text { and health }=7 \text { ) }\end{array}$ \\
\hline \multirow[b]{2}{*}{$\begin{array}{l}\text { Continuing } \\
\text { customers }\end{array}$} & \multicolumn{3}{|c|}{ New and terminated customers are excluded from all customers. } \\
\hline & $\begin{array}{l}3665 \text { (residential }= \\
3620, \text { social }=12, \\
\text { academic }=15, \\
\text { business }=11, \text { and } \\
\text { office }=7 \text { ) }\end{array}$ & $\begin{array}{l}8003(\text { residential }= \\
7881, \text { social }=42, \\
\text { academic }=44, \\
\text { business }=25, \text { and } \\
\text { office }=11)\end{array}$ & $\begin{array}{c}4640 \text { (residential }= \\
4542, \text { social }=35 \\
\text { academic }=20 \\
\text { business }=12, \text { office }= \\
26, \text { and health }=5 \text { ) }\end{array}$ \\
\hline \multirow{2}{*}{$\begin{array}{l}\text { Non-zero residential } \\
\text { customers }\end{array}$} & \multicolumn{3}{|c|}{$\begin{array}{l}\text { Only residential customers consuming at least } 1 \mathrm{~m}^{3} / \text { month are included } \\
\text { in continuing customers. }\end{array}$} \\
\hline & 3010 & 5019 & 3319 \\
\hline $\begin{array}{l}\text { Non-zero residential } \\
\text { customers }<=50 \\
\mathrm{~m}^{3} / \text { month }\end{array}$ & 2235 & 4057 & 2706 \\
\hline
\end{tabular}

\section{References}

1. World Bank Group. Reducing Inequalities in Water Supply, Sanitation, and Hygiene in the Era of the Sustainable Development Goals; World Bank: Washington, DC, USA, 2017.

2. Ortigara, A.R.C.; Kay, M.; Uhlenbrook, S. A Review of the SDG 6 Synthesis Report 2018 from an Education, Training, and Research Perspective. Water 2018, 10, 1353. [CrossRef]

3. United Nations Children's Fund (UNICEF) and World Health Organization. Progress on Household Drinking Water, Sanitation and Hygiene 2000-2017. Special Focus on Inequalities; United Nations Children's Fund (UNICEF) and World Health Organization: New York, NY, USA, 2019.

4. Machado, A.V.M.; Santos, J.A.N.; Quindeler, N.S.; Alves, L.M.C. Critical Factors for the Success of Rural Water Supply Services in Brazil. Water 2019, 11, 2180. [CrossRef]

5. Schweitzer, R.W.; Mihelcic, J.R. Assessing Sustainability of Community Management of Rural Water Systems in the Developing World. J. Water Sanit. Hyg. Dev. 2012, 2, 20-30. [CrossRef]

6. Hutchings, P.; Chan, M.Y.; Cuadrado, L.; Ezbakhe, F.; Mesa, B.; Tamekawa, C.; Franceys, R. A Systematic Review of Success Factors in the Community Management of Rural Water Supplies over the Past 30 Years. Water Policy 2015, 17, 963-983. [CrossRef]

7. Schouten, T.; Moriarty, P. Scaling up the Community Management of Rural Water Supply. Waterlines 2004, 23, 2-4. [CrossRef]

8. Kanakoudis, V.; Tsitsifli, S. Doing the urban water supply job: From privatization to remunicipalisation and the third pillar of the Performance Based Service Contracts. Water Util. J. 2014, 8, 31-46.

9. Donkor, E.A. Effect of customer satisfaction on water utility business performance. J. Awwa 2013, 105, E553-E560. [CrossRef]

10. Ohwo, O.; Agusomu, T.D. Residential Customers Satisfaction with Public Water Provision in Ojota, Nigeria. Eur. Sci. J. 2018, 14. [CrossRef]

11. Zeraebruk, K.; Mayabi, A.; Gathenya, J.; Tsige, Z. Assessment of Water Supply Services and Operational Performance of Asmara Water Supply Department (AWSD) for Development of Decision Support Tools. Environ. Nat. Resour. Res. 2014, 4, $208-222$. [CrossRef]

12. Nafi, A. Comprehensive Methodology for Overall Performance Assessment of Water Utilities. Water Resour. Manag. 2015, 29. [CrossRef]

13. UN-Water. Sustainable Development Goal 6 Synthesis Report on Water and Sanitation 2018; United Nations: New York City, NY, USA, 2018.

14. Government of Nepal. Water Resource Act, 2049 (1992); Ministry of Energy, Water Resources and Irrigation: Kathmandu, Nepal, 1992.

15. Government of Nepal. Water Service Providers Data Book, 2069-2070 (2012-2013); Sector Efficiency Improvement Unit (SEIU), Ministry of Urban Development: Kathmandu, Nepal, 2014.

16. Government of Nepal. Nepal Water Service Providers Data Book, 2070-2071 (2013-2014); Sector Efficiency Improvement Unit (SEIU), Ministry of Urban Development and Asian Development Bank, ADB Nepal Office: Kathmandu, Nepal, 2015. 
17. Government of Nepal. Water Service Providers Capacity Assessment and Benchmarking Data Year 2071-72 (2014-15) (NWSC, WSMB and KUKL); Sector Efficiency Improvement Unit (SEIU), Ministry of Water Supply and Sanitation: Kathmandu, Nepal, 2016.

18. Balacco, G.; Totaro, V.; Iacobellis, V.; Manni, A.; Spagnoletta, M.; Piccinni, A.F. Influence of COVID-19 Spread on Water Drinking Demand: The Case of Puglia Region (Southern Italy). Sustainability 2020, 12, 5919. [CrossRef]

19. Guragai, B.; Takizawa, S.; Hashimoto, T.; Oguma, K. Effects of Inequality of Supply Hours on Consumers' Coping Strategies and Perceptions of Intermittent Water Supply in Kathmandu Valley, Nepal. Sci. Total Environ. 2017, 599-600, 431-441. [CrossRef] [PubMed]

20. Keeley, B. Income Inequality: The Gap between Rich and Poor, OECD Insights; OECD Publishing: Paris, France, 2015. [CrossRef]

21. Government of Nepal. Nepal-Annual Household Survey 2015-2016; Central Bureau of Statistics, National Planning Commission Secretariat: Kathmandu, Nepal, 2018.

22. Murrar, A.; Awad, I.; Hasan, A.; Yaqob, E.; Barghothi, I.; Sadaqa, A.; Samhan, S.; Tamimi, A. The Impact of Water Price on the Financial Sustainability of the Palestinian Water Service Providers. J. Environ. Prot. 2017, 8, 1490-1508. [CrossRef]

23. Kanakoudis, V.; Papadopoulou, A.; Tsitsifli, S. Domestic Water Pricing in Greece: Mean Net Consumption Cost versus Mean Payable Amount. Fresenius Environ. Bull. 2014, 23, 2742-2749.

24. Kanakoudis, V.; Papadopoulou, A.; Tsitsifli, S. Domestic Water Pricing in Greece: A Spatial Differentiation. Desalination Water Treat. 2015, 54, 2204-2211. [CrossRef]

25. Farley, M.; Wyeth, G.; Ghazali, Z.B.M.; Istandar, A.; Singh, S. The Manager's Non-Revenue Water Handbook: A Guide to Understanding Water Losses; Dijk, N.V., Rakaskulthali, V., Kirkwood, E., Eds.; Ranhill Utilities Berhad and the United States Agency for International Development (USAID): Bangkok, Thailand, 2008.

26. Tsavdaridou, A.; Kolokytha, E.; Mentes, A. Urban Water Consumption and New Metering Technologies: Application in the City of Thessaloniki. In Proceedings of the XI Protection and Restoration of the Enivironment (PRE) Conference 2012, Thessaloniki, Greece, 3-6 July 2012; pp. 203-212. [CrossRef]

27. Khaing, K.S.; Kazama, S.; Takizawa, S. Assessment of Revenue Loss Due to Damaged Water Meters in Different Housing Types of Yangon City. Master's Thesis, The University of Tokyo, Tokyo, Japan, 2020.

28. Jang, D. A Parameter Classification System for Nonrevenue Water Management in Water Distribution Networks. Adv. Civ. Eng. 2018. [CrossRef]

29. Hope, R.; Foster, T.; Krolikowski, A.; Cohen, I. Mobile Water Payment Innovations in Urban Africa; School of Geography and the Environment and Skoll Centre for Social Entrepreneurship at Said Business School, Oxford University: Oxford, UK, 2011.

30. Amankwaa, G.; Asaaga, F.A.; Fischer, C.; Awotwe, P. Diffusion of Electronic Water Payment Innovations in Urban Ghana. Evidence from Tema Metropolis. Water 2020, 12, 1011. [CrossRef]

31. Ezemenari, K.M.; Joshi, N.K.; Blum, F.M.; Varela, G.J.; Ganz Carulla, F. Nepal Development Update: Harnessing Export Potential for a Green, Inclusive, and Resilient Recovery; World Bank Group: Washington, DC, USA, 2021.

32. Ibrahim A, S.; Memon, F.A.; Butler, D. Seasonal Variation of Rainy and Dry Season Per Capita Water Consumption in Freetown City Sierra Leone. Water 2021, 13, 499. [CrossRef]

33. Nemati, M. COVID-19 and Urban Water Consumption. University of California, Giannini Foundation of Agricultural Economics, 2020. Are Update 2020, 24, 9-11.

34. Abu-Bakar, H.; Williams, L.; Hallett, S.H. Quantifying the Impact of the COVID-19 Lockdown on Household Water Consumption Patterns in England. NPJ Clean Water 2021, 4, 1-9. [CrossRef]

35. Kalbusch, A.; Henning, E.; Brikalski, M.P.; Luca, F.V.D.; Konrath, A.C. Impact of Coronavirus (COVID-19) Spread-Prevention Actions on Urban Water Consumption. Resour. Conserv. Recycl. 2020, 163, 105098. [CrossRef] [PubMed]

36. Andey, S.P.; Kelkar, P.S. Influence of Intermittent and Continuous Modes of Water Supply on Domestic Water Consumption. Water Resour. Manag. 2009, 23, 2555-2566. [CrossRef]

37. Bradley, R.M.; Weeraratne, S.; Mediwake, T.M.M. Water use projections in Developing Countries. J. AWWA 2002, 94, 52-63. [CrossRef] 